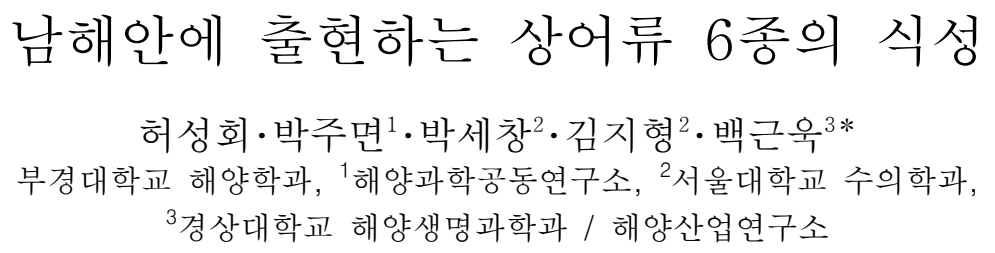

\title{
Feeding Habits of 6 Shark Species in the Southem Sea of Korea
}

\author{
Sung-Hoi Huh, Joo Myun Park ${ }^{1}$, Se Chang Park², \\ Ji Hyung $\mathrm{Kim}^{2}$ and Gun Wook Baeck ${ }^{3 *}$ \\ Department of Oceanography \& ${ }^{1}$ Korea Inter-University Institute of Ocean Science, \\ Pukyong National University, Busan 608-737, Korea \\ ${ }^{2}$ Laboratory of Aquatic Animal Medicine, College of Veterinary Medicine, \\ Seoul National University, Seoul 151-742, Korea \\ ${ }^{3}$ Department of Marine Biology \& Aquaculture / Institute of Marine Industry, \\ Gyeongsang National University, Tongyeong 650-160, Korea
}

The feeding habits of six shark species, Scyliorhinus torazame, Mustelus manazo, Squalus megalops, Isurus oxyrinchus, Alopias pelagicus, and Carcharhinus plumbeus were studied using the stomach contents of 463 specimens collected between January and February 2007 in the southern sea of Korea. They consumed different prey items. S. torazame preyed mainly crustaceans, and M. manazo on crustaceans and fishes. $S$. megalops, I. oxyrinchus, A. pelagicus, and C. plumbeus consumed predominately fishes. Non-metric multi-dimensional scaling (NMDS) ordination plots emphasized that dietary similarities separated thesix shark species into three trophic groups based on similarities in percentage Index of Relative Importance (\%IRI): Group I (crustacean feeders), Group II (fish and crustacean feeders), and Group III (fish feeders).

Key words: Feeding habits, Sharks, NMDS, Southern sea of Korea

\section{서 론}

상어는 연골어강 (Class Chondrichthyes) 판새아강 (Subclass Elasmobranchii)에 속하는 어류로 우리나라에 출현하는 상어 는 판새아강에 속하는 어류중 홍어목을 제외한 8 개 분류군에 속하는 어류를 말한다 (Yoon, 2002). 상어류는 전 세계적으로 약 400여종이 출현하는 것으로 알려져 있으며 (Garman, 1997), 우리나라 연근해에서는 총 8 목 17 과 41 종의 상어류가 출현하 는 것으로 보고되어 있다 (Kim et al., 2005). 그러나 Choi (2009) 는 이 중 일부 종은 연근해의 분포가 확실하지 않아 연근해 상어류 분포에 대한 면밀한 검토가 필요하다고 하였다.

상어류를 포함하는 연골어류는 중요한 상업성 어종으로 최근 이들의 근육, 연골, 간유, 지느러미에 관한 상업적 이용이 전 세계적으로 증가하는 추세에 있다 (Stehmann, 2002). 남해 안에 출현하는 상어류는 주로 저인망과 선망에 의해 어획되었 다 (KNSO, 1990-2009). 1990년대 이후 우리나라 연안에 출현 하는 상어류의 연간 어획량을 살펴보면 (Fig. 1), 1995년 이전 에는 연간 1,000 톤 이상의 어획량을 나타내었으나 그 이후 어획량이 감소하여 2009년에는 약 340톤이 어획되었다. 1993 년에는 5,000 톤 이상이 어획되어 1990년대 이후 가장 많은 어획량을 나타내었는데 이는 대형선망에 의해 상어류가 3,000 톤 이상 어획되었기 때문이었다.

\footnotetext{
*Corresponding author: gwbaeck@gun.ac.kr
}

최근 전 지구적인 기후변동에 따른 해양의 수온 상승으로 많은 아열대지역 위험 상어류의 서식영역이 북상하게 되었으 며 온대해역에서 이들에 의한 인간 공격이 종종 보고되고 있 다. 특히 최근 우리나라 주변해역에서 백상아리(Carcharodon carcharias), 귀상어 (Sphyrna zygaena) 등의 출현량 증가가

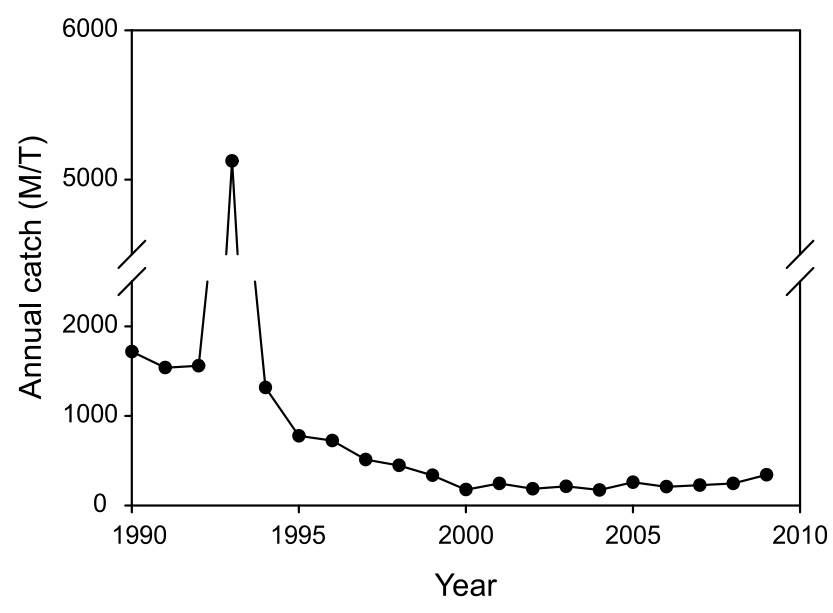

Fig. 1. Annual yield of shark species in Korean waters from 1990 to 2009. 
사람들에게 위협이 되고 있다 (Choi, 2009). 그러나 이들에 대한 정확한 생태적 정보의 부족으로 출현량 증가에 대한 정확한 원인을 밝혀내지 못하고 있는 실정이다. 전 세계적으 로 대부분 상어류는 그들의 큰 크기, 넓은 회유경로, 낮은 출현량 등으로 인한 시료 채집의 어려움 때문에 그들의 생태 학적 연구가 부족한 실정이다 (Wetherbee et al., 1990).

섭식생태 (trophic ecology)에 관한 연구는 생태계내에서 어류의 기능적 역할을 이해하는데 중요한 요소가 된다 (Wootton, 1990; Brodeur and Pearcy, 1992). 대부분 상어류는 어식성어류 (fish feeder) 이고 일부 소형 상어류는 갑각류를 주로 섭식하였다. 그리고 Pacific sleeper shark (Somniosus pacificus)와 같은 대형 상어류는 어류 외에 해양포유류도 섭식 하는 것으로 보고되었다 (Sigler et al., 2006). 이와 같이 대부분 상어류는 해양생태계 내에서 어류를 섭식하는 최상위 포식자 이고 그들의 섭식은 해양생태계 먹이망에 큰 영향을 미칠 수 있다 (Compagno, 1984). 따라서 이들의 섭식생태 연구는 생태계 먹이망을 이해하는데 중요한 요소가 될 수 있다. 본 연구는 우리나라 남해안에 출현하는 상어류의 위내용물 분석 을 통하여 상어류의 주 먹이생물과 체장군별 먹이조성, 섭식형 태를 조사하였고 과거의 연구들과 섭식형태를 비교해 보았다.

\section{재료 및 방법}

본 연구에 사용된 상어의 시료는 2007년 1월부터 2월까지 한국 남해안에서 채집된 시료를 매일 오전 중매인을 통하여 자갈치 위판장에서 구입하였다. 채집된 시료는 냉장 보관하여 실험실로 운반한 뒤 실험실에서 각 개체의 체장 $(0.1 \mathrm{~cm})$ 을 측정한 뒤 위 부분을 분리하여 위내용물을 분석하였다. 위내 용물 중 출현하는 먹이생물은 Takeda (1982), NFRDI (2001), Yoon (2002) 등을 이용하여 동정하였고, 종류별로 개체수를 계수하였다. 그 후 건조기에 넣고 $80^{\circ} \mathrm{C}$ 에서 24 시간 건조시킨 뒤, 전자저울을 이용하여 먹이생물 종류별로 건조중량을 측정 하였다. 상어류는 채집된 어구 내에서 어구의 충격에 의해 함께 채집된 어류를 섭식할 가능성이 있으나, 본 연구에서 상어류의 위내용물 중 발견된 먹이생물은 소화정도가 어느 정도 진행된 상태였기 때문에 이러한 가능성을 배제할 수 있었다.

위 내용물의 분석 결과는 각 먹이생물에 대한 출현빈도, 먹이생물의 개체수비 및 건조중량비로 나타내었다. 출현빈도 $(\% \mathrm{~F})$ 는 다음과 같이 구하였다.

$$
\% F=A_{i} / N \times 100
$$

여기서 $A i$ 는 해당 먹이생물이 위내용물 중 발견된 상어류의 개체수이고, $N$ 은 위속에 내용물이 있었던 상어류의 개체수이다.

섭식된 먹이생물의 상대중요성지수 (index of relative importance, IRI)는 Pinkas et al. (1971)의 식을 이용하여 구하였다.

$$
I R I=(\% N+\% W) \times \% F
$$

여기서, $\% N$ 은 먹이생물 총 개체수에 대한 백분율이며, $\% W$ 는 먹이생물 총 건조중량에 대한 백분율이고, $\% F$ 는 각 먹이생 물의 출현빈도이다. 또한 각 먹이생물의 상대중요성지수를 백분율로 환산하여 상대중요성지수비 $(\% I R I)$ 를 구하였다.

각 어종의 먹이다양도지수 $\left(\mathrm{H}^{\prime}\right)$ 는 Shannon-Weaver 식을 사용하여 나타내었다(Petraitis, 1979; Brodeur and Pearcy, 1990).

$$
H^{\prime}=\sum\left(P_{i j} \log 2^{p_{i j}}\right)
$$

여기서 $P i j$ 는 포식자 $j$ 의 위내용물에서 $i$ 먹이생물의 백분 율이다.

채집된 상어류 중 우점하는 상위 6종의 종명 code는 두툽상 어 (ST, Scyliorhinus torazame), 별상어 (MM, Mustelus manazo), 모조리상어 (SM, Squalus megalops), 청상아리(IO, Isurus oxyrinchus), 환도상어 (AP, Alopias pelagicus), 흉상어 $(\mathrm{CP}$, Carcharhinus plumbeus)와 같이 나타내었고, 크기군별 먹이조성을 나타내기 위하여 각 종을 다음과 같이 크기군을 구분하였다 두툽상어 (small, 10 20 cm; medium, 20 30 cm; large, 30 40 cm), 별상어 (small, 10 20 cm; medium, 20 30 $\mathrm{cm}$; large, 30 40 cm), 모조리상어 (small, 70 100 cm; medium, $100 \sim 120 \mathrm{~cm}$; large, 120 140 cm), 청상아리 (medium, 80 200 $\mathrm{cm}$; large, 200 280 cm), 환도상어 (medium, 140 200 cm; large, 200 350 cm), 흉상어 (medium, 80 120 cm; large, 120 200 cm).

채집된 상어류 사이의 먹이생물 유사도는 Bray-Curtis 유사 도 지수를 사용하여 분석하였고, 분석결과는 비모수다차원척 도법 (non-metric multi-dimensional scaling, NMDS)을 사용하 여 도식화하였다.

\section{결 과}

채집 개체수와 체장분포

본 연구의 조사기간동안 총 10 종의 상어류가 양륙되는 것을 확인하였다. 두툽상어 (Scyliorhinus torazame)가 182개체로 가 장 많았으며, 그 다음으로 별상어 (Mustelus manazo)가 111개 체, 모조리상어 (Squalus megalops)가 51개체, 청상아리 (Isurus oxyrinchus)가 50개체, 환도상어 (Alopias pelagicus)가 37개체, 흥상어 (Carcharhinus plumbeus)가 32개체, 무태상어 (Carcharhinus brachyurus)가 21개체, 귀상어 (Sphyrna zygaena) 가 5개체, 악상어 (Lamna ditropis)가 3 개체, 물범상어 (Halaelurus buergeri)가 2개체 순으로 채집되었다. 이 중 30개 체 이상 채집된 6종을 대상으로 위내용물을 분석하였다. 본 조사에서는 한명의 중개인을 대상으로 시료를 구입하였기 때 문에 양륙되는 전체 상어류의 종조성을 파악하기는 힘들었다.

채집된 상어류 중 두툽상어가 전장 $13.1 \sim 38.5 \mathrm{~cm}$ 로 가장 작았으 며, 청상아리와 환도상어가 각각 전장 $87.2 \sim 272.8 \mathrm{~cm}$ 와 140.8 340.1 $\mathrm{cm}$ 의 범위를 보여 가장 컸다. 별상어, 모조리상어, 흉상어는 100 $\mathrm{cm}$ 전후의 체장범위는 보여 중간 크기의 상어류 였다 (Fig. 2). 

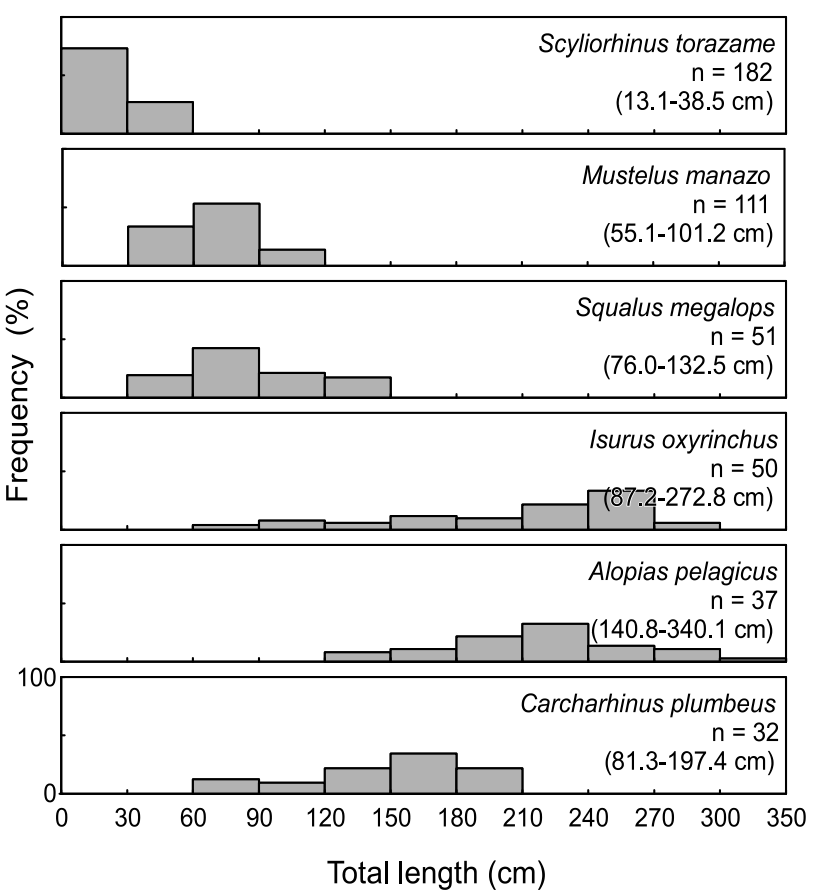

Fig. 2. Size distribution of 6 shark species collected in the Jagalchi fish market.

\section{위내용물의 조성}

총 463 개체의 상어류의 위내용물을 분석한 결과 총 9 개의 분류군에 속하는 먹이생물이 발견되었는데, 두툽상어의 위내 용물에서 7 개 분류군의 먹이생물이 발견되어 가장 많았고, 청상아리, 환도상어, 흉상어의 위내용물에서 가장 적은 2 개 분류군의 먹이생물이 발견되었다 (Table 1). 공복율은 12.1 $32.4 \%$ 의 범위를 보였는데 두툽상어가 가장 낮았고 환도상어 가 가장 높았다. 먹이생물의 다양도지수는 0.08 1.48의 범위 를 보였는데, 두툽상어가 가장 높았고 청상아리가 가장 낮았 다 (Table 1).

Table 1. Summary of six shark species by sampling in the southern sea of Korea in 2007

\begin{tabular}{lccccccc}
\hline & & \multicolumn{5}{c}{ Stomachs } \\
\cline { 3 - 8 } \multicolumn{1}{c}{ Species } & Code & Total & empty & $\begin{array}{c}\text { empty } \\
(\%)\end{array}$ & N & H \\
\hline Scyliorhinus torazame & ST & 182 & 22 & 12.1 & 7 & 1.48 \\
Mustelus manazo & MM & 111 & 15 & 13.5 & 6 & 1.04 \\
Squalus megalops & SM & 51 & 13 & 25.5 & 4 & 0.72 \\
Isurus oxyrinchus & IO & 50 & 13 & 26.0 & 2 & 0.08 \\
Alopias pelagicus & AP & 37 & 12 & 32.4 & 2 & 0.16 \\
Carcharhinus plumbeus & $\mathrm{CP}$ & 32 & 7 & 21.9 & 2 & 0.40 \\
\hline
\end{tabular}

(N : Total number of prey taxa, H : Diet diversity index)
주요 상어류의 위내용물 분석결과는 Table 2 와 같다. 총 182 개체의 두툽상어 중 위내용물이 발견된 160 개체의 위내용 물을 분석한 결과, 두툽상어의 가장 중요한 먹이생물은 출현

Table 2. Composition of the stomach contents of six shark species by frequency of occurrence, number, dry weight and index of relative importance (IRI)

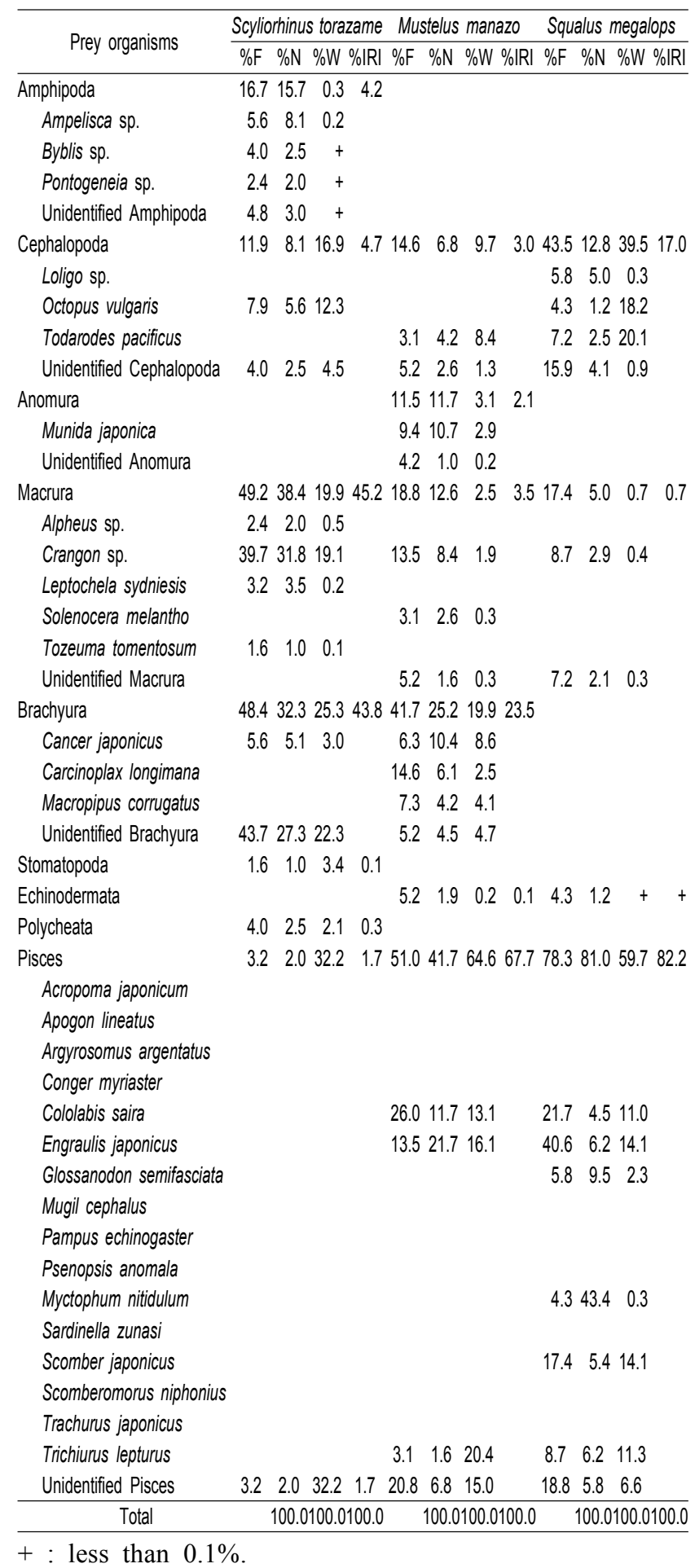


Table 2. (continued)

\begin{tabular}{|c|c|c|c|c|c|c|c|c|c|c|}
\hline \multirow{2}{*}{ Prey organisms } & \multicolumn{3}{|c|}{ Isurus oxyrinchus } & \multicolumn{4}{|c|}{ Alopias pelagicus } & \multicolumn{3}{|c|}{ Carcharhinus plumbeus } \\
\hline & $\% \mathrm{~F}$ & $\% \mathrm{~N}$ & $\% \mathrm{~W} \% \mid \mathrm{RI}$ & $\% \mathrm{~F}$ & $\% \mathrm{~N}$ & $\% W \%$ & $\%|R|$ & $\% \mathrm{~F} \%$ & $\% \mathrm{~N}$ & $\% \mathrm{~W} \% \mathrm{RI}$ \\
\hline \multicolumn{11}{|l|}{ Amphipoda } \\
\hline \multicolumn{11}{|l|}{ Ampelisca sp. } \\
\hline \multicolumn{11}{|l|}{ Byblis sp. } \\
\hline \multicolumn{11}{|l|}{ Pontogeneia sp. } \\
\hline \multicolumn{11}{|l|}{ Unidentified Amphipoda } \\
\hline Cephalopoda & 34.4 & 12.4 & 1.53 .1 & 114.3 & 3.8 & 3.9 & 0.73 & 31.0 & 6.0 & 13.64 .6 \\
\hline \multicolumn{11}{|l|}{ Loligo sp. } \\
\hline \multicolumn{11}{|l|}{ Octopus vulgaris } \\
\hline Todarodes pacificus & 9.4 & 3.4 & 1.0 & 8.6 & 2.2 & 3.3 & & 10.3 & 3.2 & 9.1 \\
\hline Unidentified Cephalopoda & 25.0 & 9.0 & 0.5 & 5.7 & 1.6 & 0.6 & & 20.7 & 2.8 & 4.4 \\
\hline \multicolumn{11}{|c|}{ Anomura } \\
\hline \multicolumn{11}{|l|}{ Munida japonica } \\
\hline \multicolumn{11}{|l|}{ Unidentified Anomura } \\
\hline \multicolumn{11}{|l|}{ Macrura } \\
\hline \multicolumn{11}{|l|}{ Alpheus sp. } \\
\hline \multicolumn{11}{|l|}{ Crangon sp. } \\
\hline \multicolumn{11}{|l|}{ Leptochela sydniesis } \\
\hline \multicolumn{11}{|l|}{ Solenocera melantho } \\
\hline Tozeuma tomentosum & & & & & & & & & & \\
\hline Unidentified Macrura & & & & & & & & & & \\
\hline Brachyura & & & & & & & & & & \\
\hline Cancer japonicus & & & & & & & & & & \\
\hline Carcinoplax longimana & & & & & & & & & & \\
\hline Macropipus corrugatus & & & & & & & & & & \\
\hline Unidentified Brachyura & & & & & & & & & & \\
\hline Stomatopoda & & & & & & & & & & \\
\hline Echinodermata & & & & & & & & & & \\
\hline Polycheata & & & & & & & & & & \\
\hline Pisces & 81.3 & 87.6 & 98.596 .9 & 985.7 & 96.2 & 96.19 & 99.36 & 69.09 & 94.0 & 86.495 .4 \\
\hline Acropoma japonicum & & & & 14.3 & 0.8 & 0.5 & & 17.2 & 9.3 & 5.2 \\
\hline Apogon lineatus & & & & & & & & 3.4 & 2.3 & 0.4 \\
\hline Argyrosomus argentatus & & & & 5.7 & 1.1 & 6.6 & & & & \\
\hline Conger myriaster & & & & & & & & 10.3 & 1.4 & 1.9 \\
\hline Cololabis saira & & & & 11.4 & 4.0 & 1.2 & & & & \\
\hline Engraulis japonicus & 15.6 & 59.3 & 9.2 & 37.1 & 57.1 & 28.5 & & 31.06 & 63.0 & 29.0 \\
\hline Glossanodon semifasciata & 12.5 & 2.8 & 0.3 & & & & & & & \\
\hline Mugil cephalus & 21.9 & 5.5 & 43.8 & 8.6 & 1.3 & 4.2 & & 6.9 & 1.9 & 4.2 \\
\hline Pampus echinogaster & & & & 2.9 & 1.6 & 2.6 & & 13.8 & 2.3 & 5.5 \\
\hline Psenopsis anomala & & & & 11.4 & 1.6 & 11.0 & & 17.2 & 3.7 & 20.5 \\
\hline Myctophum nitidulum & & & & & & & & & & \\
\hline Sardinella zunasi & & & & 8.6 & 1.3 & 0.7 & & & & \\
\hline Scomber japonicus & 12.5 & 9.0 & 21.5 & & & & & & & \\
\hline Scomberomorus niphonius & s 6.3 & 1.4 & 10.4 & 5.7 & 1.9 & 10.2 & & & & \\
\hline Trachurus japonicus & 9.4 & 2.1 & 4.8 & 28.6 & 25.5 & 30.6 & & 24.1 & 6.0 & 15.9 \\
\hline Trichiurus lepturus & 25.0 & 4.1 & 7.5 & & & & & 6.9 & 1.4 & 1.5 \\
\hline Unidentified Pisces & 15.6 & 3.4 & 1.0 & & & & & 20.7 & 2.8 & 2.3 \\
\hline Total & 100.0 & 100.01 & 100.0 & 100.01 & 100.01 & 100.0 & & 100.010 & & 100.0 \\
\hline
\end{tabular}

+ : less than $0.1 \%$

빈도 $49.2 \%$, 개체수비 $38.4 \%$, 건조중량비 $19.9 \%$, 상대중요성 지수비 $45.2 \%$ 를 나타낸 새우류 (Macrura)와 출현빈도 $48.4 \%$, 개체수비 $32.3 \%$, 건조중량비 $25.3 \%$, 상대중요성지수비 $43.8 \%$
를 나타낸 게류 (Brachyura)였다. 그 다음으로 중요한 먹이생 물은 각각 상대중요성지수비 $4.7 \%, 4.2 \%, 1.7 \%$ 를 나타낸 두족 류 (Cephalopoda), 단각류 (Amphipoda), 어류 (Pisces)였다. 그 외 다모류 (Polychaeta), 갯가재류 (Stomatopoda)가 발견되었으 나 그 양은 많지 않았다. 별상어는 총 111 개체가 채집되었는데 위내용물이 발견된 96개체의 위내용물 분석 결과, 어류와 게 류가 각각 출현빈도 $51.0 \%$ 와 $41.7 \%$, 개체수비 $41.7 \%$ 와 $25.2 \%$, 건조중량비 $64.6 \%$ 와 $19.9 \%$, 상대중요성지수비 $67.7 \%$ 와 $23.5 \%$ 를 나타내어 중요한 먹이생물이었다. 그 외 새우류, 두족류, 집게류 (Anomura), 거미불가사리류 (Echinodermata)가 발견되 었으나 그 양은 많지 않았다. 모조리상어는 51개체가 채집되 었고, 위내용물이 발견된 38 개체의 위내용물 중 어류가 출현 빈도 $78.3 \%$, 개체수비 $81.0 \%$, 건조중량비 $59.7 \%$, 상대중요성 지수비 $82.2 \%$ 를 나타내어 가장 중요한 먹이생물이었다. 그 다음으로 두족류가 상대중요성지수비 $17.0 \%$ 를 나타내었다. 새우류와 거미불가사리류도 모조리상어의 위내용물 중 발견 되었으나 그 양은 많지 않았다. 총 50 개체의 청상아리 중 위내 용물이 발견된 37 개체의 청상아리 위내용물에서 어류가 출현 빈도 $81.3 \%$, 개체수비 $87.6 \%$, 건조중량비 $98.5 \%$, 상대중요성 지수비 $96.9 \%$ 를 나타내어 우점하였다. 그 다음으로 두족류가 상대중요성지수비 $3.1 \%$ 를 차지하였다. 환도상어는 37 개체가 채집되었고 위내용물이 발견된 25 개체의 위내용물 분석결과 가장 중요한 먹이생물은 출현빈도 $85.7 \%$, 개체수비 $96.2 \%$, 건조중량비 $96.1 \%$, 상대중요성지수비 $99.3 \%$ 를 나타낸 어류였 다. 어류 다음으로 두족류가 상대중요성지수비 $0.7 \%$ 을 차지 하였다. 총 32 개체의 흥상어 중에서 위내용물이 발견된 25 개 체에서 가장 중요한 먹이생물은 출현빈도 $69.0 \%$, 개체수비 $94.0 \%$, 건조중량비 $86.4 \%$, 상대중요성지수비 $95.4 \%$ 를 나타낸 어류였다. 어류 다음으로 두족류가 상대중요성지수비 $4.6 \%$ 를 나타내었다.

Table 3. Size related changes in the diet composition of 6 sharks species

\begin{tabular}{|c|c|c|c|c|c|c|c|c|c|c|c|c|c|c|}
\hline \multirow{2}{*}{$\begin{array}{l}\text { Specie codes } \\
\text { Size class* }\end{array}$} & \multicolumn{3}{|c|}{ ST } & \multicolumn{3}{|c|}{ MM } & \multicolumn{3}{|c|}{ SM } & \multicolumn{2}{|c|}{10} & \multicolumn{2}{|c|}{$A P$} & \multirow{2}{*}{$\frac{\mathrm{CP}}{\mathrm{M} \mathrm{L}}$} \\
\hline & $S$ & M & $\mathrm{L}$ & $S$ & M & L & S & M & L & M & L & M & L & \\
\hline \multicolumn{15}{|l|}{ Prey items ${ }^{* *}$} \\
\hline Amphipoda & 0 & 0 & & & & & & & & & & & & \\
\hline Cephalopoda & 0 & (C) & 0 & 0 & 0 & & (a) & (C) & (a) & 0 & 0 & 0 & 0 & 0 \\
\hline Anomura & & & & 0 & 0 & 0 & & & & & & & & \\
\hline Macrura & (C) & 0 & & 0 & 0 & 0 & 0 & 0 & & & & & & \\
\hline Branchyura & (C) & (C) & 0 & $\bullet$ & $\bigcirc$ & 0 & & & & & & & & \\
\hline Stomatopoda & & 0 & & & & & & & & & & & & \\
\hline \multicolumn{15}{|l|}{ Echinodermata } \\
\hline Polychaeta & 0 & & & & & & & & & & & & & \\
\hline Pisces & & & $\bullet$ & (C) & 0 & & $\bullet$ & (C) & 0 & 0 & 0 & 0 & 0 & 0 \\
\hline
\end{tabular}

* S: small, M: medium, L: large.

** $\bigcirc-30 \%$, ○ 30-60\%, 60-100\% (by dry weight). 
체장군별 먹이조성

6종 상어류의 체장군별 먹이조성을 3 개의 체장군 (small, medium, large)으로 구분하여 살펴보았다 (Table 3). 두툽상어 의 경우 전 체장군에서 갑각류가 중요한 먹이생물이었지만, 가장 큰 체장군에서 어류의 섭식이 많았다. 별상어는 작은 체장 군에서는 갑각류의 섭식이 많았고 체장의 증가에 따라 갑각류 의 비율은 감소하고 어류의 비율이 증가하였다. 모조리상어, 청상아리, 환도상어, 흉상어의 경우 전 체장군에서 어류가 중 요한 먹이생물이었고, 그 다음으로 두족류를 섭식하였다.

Table 4. Diet similarity coefficients among 6 sharks species in the southern sea of Korea, 2007

\begin{tabular}{c|cccccc}
\hline Species & ST & MM & SM & IO & AP & CP \\
\hline ST & & & & & & \\
MM & 51.07 & & & & & \\
SM & 25.29 & 67.67 & & & & \\
IO & 19.56 & 66.16 & 83.46 & & & \\
AP & 14.02 & 61.86 & 78.77 & 95.34 & & \\
CP & 21.80 & 65.49 & 85.40 & 98.04 & 93.37 & \\
\hline
\end{tabular}

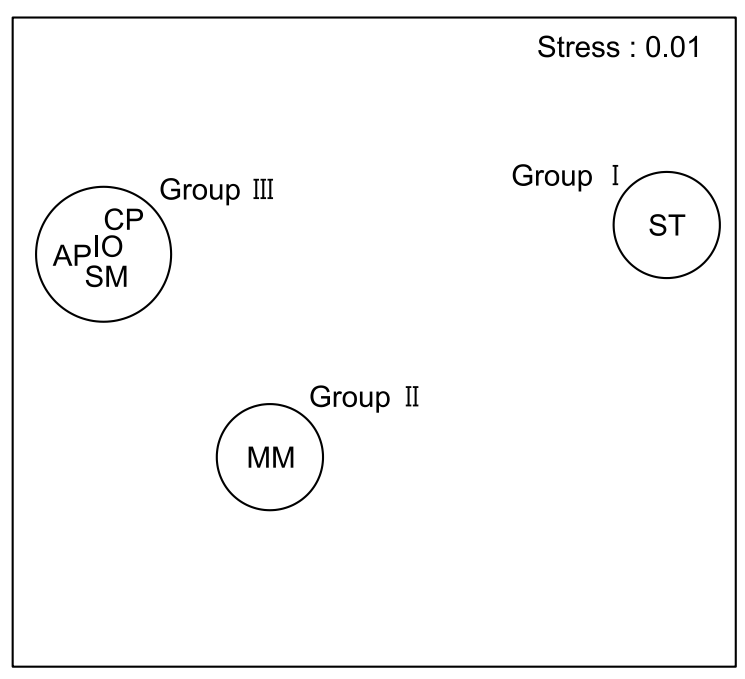

Fig. 3. Classification of feeding groups based on an NMDS of diet similarity index of the 6 shark species collected in the southern sea of Korea.

\section{먹이생물 유사도}

먹이생물의 상대중요성지수비 (\%IRI)를 사용한 6종 상어류 사이의 먹이유사도지수는 14.02 98.04의 범위를 보였다 (Table 4). 15 개의 종간 유사도지수 중에서 5 개가 $80 \%$ 이상이 었고, 3 개가 $90 \%$ 이상이었다. 가장 높은 유사도 값은 청상아리 와 흉상어 사이에서 나타났고 가장 낮은 값은 두툽상어와 환도상어 사이에서 나타났다. 먹이유사도지수를 사용한 6종 사이의 위내용물조성의 차이는 NMDS 분석에 의해 공간적으 로 3 개의 섭식그룹으로 구분할 수 있었다 (Fig. 3). 첫 번째
그룹 (Group I 은 갑각류를 주로 섭식한 어종으로 두툽상어가 속하였다. 두 번째 그룹 (Group II은 어류와 갑각류를 주로 섭식한 그룹으로 별상어가 속하였다. 세 번째 그룹 (GroupIII 은 어류를 주로 섭식한 그룹으로 모조리상어, 청상아리, 환도 상어, 흉상어가 속하였다.

\section{고 찰}

지금까지 조사되어진 자료에 의하면 우리나라 연근해에서 는 총 41 종의 상어류가 출현하는 것으로 보고되었는데 $(\mathrm{Kim}$ et al., 2005), 남해안 (제주도 포함)이 40종으로 가장 많았으며, 서해안이 18 종, 동해안이 15 종 출현하는 것으로 보고되었다 (Choi, 2009). 본 연구에서는 남해안 출현종에 비해 훨씬 적은 10 종이 채집되었는데, 이는 한정된 지역에 양륙되는 시료를 확보하였기 때문이었다.

어류의 식성연구에서 먹이다양도 지수는 얼마나 다양한 먹이 종류를 섭식 하였는지를 나타내는 지표이다. 본 연구에 서 상어류의 먹이생물의 다양도지수는 $0.08 \sim 1.48$ 의 범위를 보였는데, 어류의 섭식이 높았던 모조리상어, 청상아리, 환도 상어, 흥상어가 두툽상어, 별상어 보다 낮은 값을 나타내었다. 이는 어식성 상어류가 다른 먹이생물에 비해 먹이생물로써 어류에 대한 의존도가 높았기 때문이었다.

본 연구에서 6종의 상어류는 먹이생물의 종류에 따라 갑각 류식자 (Crustacean feeder), 어류-갑각류식자 (Fish-crustacean feeder), 어식성어류 (Fish feeder)로 구분할 수 있었다 (Fig. 3). 지금까지 전 세계적으로 연구된 많은 상어류의 식성연구에 서도 먹이생물에 따라 위와 같이 구분할 수 있었는데 그들이 속해있는 과 (Family)에 따라 먹이생물의 차이를 나타내었다 (Table 5). 고래상어 (Rhincodon typus)를 포함하는 대부분 수염 상어목 (Orectolobiformes) 상어류는 여과식자 (filter feeding predator)로 플랑크톤을 섭식하는 것으로 알려져 있다. 본 연구 의 두툽상어가 속하는 흥상어목 (Carcharhiniformes)의 두툽상 어과 (Scyliorhinidae) 상어류는 최대 체장이 $100 \mathrm{~cm}$ 인 비교적 크기가 작은 소형 상어류로 갑각류를 주로 섭식하는 상어류이 며 갑각류식자 (Crustacean feeder)로 분류할 수 있었다. 흉상어 목의 까치상어과 (Triakidae)에 속하는 상어류는 최대 체장이 100 $150 \mathrm{~cm}$ 의 중형 상어류로 (Kim et al., 2005) 어류와 갑각류 를 주로 섭이하는 어류-갑각류 식자 (Fish-crustacean feeder)로 구분할 수 있었다. 비록 몇몇 연구에서 이들의 위내용물 중 갑각류가 가장 중요한 먹이생물로 나타났지만, 이들은 먹이생 물로써 갑각류에 완전히 의존하지 않고 어류 또한 많이 섭식 하는 것으로 나타났다 (Kamura and Hachimoto, 2004; Jardas et al., 2007). 그 외 흉상어목의 흉상어과 (Carcharhinidae), 악상 어목 (Lamniformes)의 환도상어과 (Alopiidae)와 악상어 (Lamnidae)과, 돔발상어목 (Squatiniformes)의 Somniosidae와 돔발상어과 (Squalidae)에 속하는 상어류는 대부분 최대 체장 $200 \mathrm{~cm}$ 이상의 중대형 상어류로 어류를 주로 섭식하는 어식성 어류 (Fish feeder)로 구분할 수 있었다. 특히 Somoniosidae의 genus Somniosus에 속하는 상어류는 북극해 주변에 주로 서식 하고 최대 체장 $400 \mathrm{~cm}$ 이상의 대형 상어류 (Campagno, 1984) 
Table 5. Comparison of prey items between worldwide shark species

\begin{tabular}{|c|c|c|c|c|c|}
\hline Order & Family & Species & Feeding type & Study area & Reference \\
\hline Orectolobiformes & Rhincodontidae & Rhincodon typus & Planktonic feeder & Western Australia Waters & Campagno (1984) \\
\hline \multirow[t]{11}{*}{ Carcharhiniformes } & Scyliorhinidae & Galeusmelastomus & Crustacean feeder & Mediterranean Sea & Fanelli et al. (2009) \\
\hline & & Schroederichthys bivius & Crustacean feeder & Beagle Channel & Matallanas et al. (1993) \\
\hline & & Scyliorhinus torazame & Crustacean feeder & Southern Sea of Korea & Present study \\
\hline & Triakidae & Mustelusgriseus & Crustacean feeder & Seto Inland Sea & Kamura \& Hachimoto (2004) \\
\hline & & M.manazo & Fish-crustacean feeder & Southern Sea of Korea & Present study \\
\hline & & M.manazo & Crustacean feeder & Seto Inland Sea & Kamura \& Hachimoto (2004) \\
\hline & & M.mustelus & Fish-crustacean feeder & Mediterranean Sea & Saidï et al. (2009) \\
\hline & & M.punctulatus & Fish-crustacean feeder & Adriatic Sea & Jardas et al. (2007) \\
\hline & Carcharhinidae & Carcharhinus plumbeus & Fish feeder & Central Pacific & McElroy et al. (2006) \\
\hline & & C. plumbeus & Fish feeder & Southern Sea of Korea & Present study \\
\hline & & Prionaceglauca & Fish-mollusk feeder & North-Western Pacific & Kubodera et al. (2007) \\
\hline \multirow[t]{4}{*}{ Lamniformes } & Alopiidae & Alopiaspelagicus & Fish feeder & Southern Sea of Korea & Present study \\
\hline & & A.superciliosus & Fish feeder & California waters & Preti et al. (2008) \\
\hline & Lamnidae & Isurus oxyrinchus & Fish feeder & Southern Sea of Korea & Present study \\
\hline & & Lamna ditropis & Fish-mollusk feeder & North-Western Pacific & Kubodera et al. (2007) \\
\hline \multirow[t]{4}{*}{ Squatiniformes } & Somniosidae & Somniosus antarcticus & Fish-mammal feeder & Greenland Waters & Yano et al. (2007) \\
\hline & & S. microcephalus & Fish-mammal feeder & Greenland Waters & Yano et al. (2007) \\
\hline & & S. pacificus & Fish-mollusk feeder & North-Eastern Pacific & Sigler et al (2006) \\
\hline & Squalidae & Squalus megalops & Fish feeder & Southern Sea of Korea & Present study \\
\hline
\end{tabular}

이고, 어류 외에 해양포유류도 섭식하는 것으로 알려져 있다. 대부분 어식성 상어류는 어류 외에 두족류 또한 많이 섭식하 는 것으로 나타났는데, 본 연구에서도 모조리상어, 청상아리, 환도상어, 흉상어의 위내용물 중에서 어류 다음으로 두족류가 중요한 먹이생물로 나타났다 (Table 2). 이상을 종합해 보면 전 세계에 출현하는 상어류는 크게 플랑크톤식자, 갑각류식 자, 어류-갑각류식자, 어식성어류로 구분할 수 있다.

본 연구에서 모조리상어, 청상아리, 환도상어, 흉상어의 위 내용물 중 비교적 큰 크기의 어류인 고등어 (Scomber japonicus), 삼치 (Scomberomorus niphonius)가 발견되었다. 고 등어는 멸치를, 삼치는 멸치와 고등어를 주로 섭식하는 어식 성어류로 알려져 있는데 (Huh et al., 2006; Yoon et al., 2007), Huh et al. (2006)은 한국 남해안 생태계 먹이망에서 멸치 $\rightarrow$ 고 등어 $\rightarrow$ 삼치로의 먹이사슬이 존재한다고 하였고, 삼치가 남해 안 생태계에서 상위 위치의 포식자라고 하였다. 고등어와 삼 치를 포함하는 고등어과 (Scombridae) 어류는 대부분 어식성 어류이며 경골어류 중 상위 포식자이다 (Huh et al., 2006; Yoon et al., 2008). 본 연구의 모조리상어, 청상아리, 환도상어 의 위내용물 중에서 고등어와 삼치가 발견되었으며 특히 청상 아리에 의한 이들의 포식이 가장 높았다. 따라서 같은 상어류 상호간에 포식이 없는 한 상어류는 한국 남해안 생태계에서 천적이 없는 최상위 포식자 (apex predator)로 판단할 수 있다.

거의 모든 상어류는 난태생 어류로 어미의 몸에서 어느 정도 성장한 뒤 부화하기 때문에 다른 경골어류에 비하여
어린 개체의 크기가 상당히 크다. 본 연구의 대상종인 두툽상 어의 부화 체장은 전장 약 $12 \mathrm{~cm}$, 별상어는 약 $30 \mathrm{~cm}$, 모조리상 어는 약 20 24 cm, 청상아리는 약 $60 ~ 70 \mathrm{~cm}$, 환도상어는 약 $100 \mathrm{~cm}$, 흥상어는 55 75 cm로 알려져 있다 (Chiba, 1998; Kim et al., 2005). 본 연구에서는 두툽상어와 별상어를 제외하고는 대부분 큰 체장의 성어만 채집되었으며 충분한 분석개체수가 확보되지 않아 성장에 따른 먹이생물 변화 결과를 도출하기 힘들었다 (Table 3). 두툽상어의 경우 전 체장개체에서 갑각류 가 중요한 먹이생물로 나타났다. 따라서 두툽상어를 포함한 갑각류식자인 두툽상어과 상어류는 전 생활사에 걸쳐 갑각류 를 주로 섭식할 것으로 판단된다. 별상어와 같은 속에 속하는 Mustelus mustelus 의 경우 비교적 작은 체장에서는 갑각류를 더 많이 섭식하였으며 체장의 증가에 따라 어류의 섭식비율이 증가하였다 (Saidi et al., 2009). 따라서 별상어를 포함하는 어류-갑각류식자인 까치상어과 어류는 유사한 결과를 나타낼 것으로 판단된다. 어식성 상어류의 성장에 따른 먹이생물의 변화 양상을 살펴보면, 돔발상어과에 속하는 Etmopterus spinax의 경우 작은 체장에서는 어류와 갑각류, 큰 체장에서는 어류를 주로 섭식하였으며 (Fanelli et al., 2008), Sphyrna lewini 또한 유어 (juvenile) 시기에 어류와 갑각류가 중요한 먹이생물 이었다 (Bush, 2003). 그리고 Somniosus 상어류인 S. pacificus의 경우 대부분 크기군에서 어류가 가장 중요한 먹이생물이었지 만 $200 \mathrm{~cm}$ 이상에서 해양포유류의 섭식이 증가하였다 (Sigler et al., 2006). 따라서 대부분 어식성 상어류는 다른 상어류에 
비해 부화 체장이 비교적 크기 때문에 부화 후 어류와 갑각류 를 주로 섭식하였으며 성장하면서 어류를 주로 섭식할 것으로 판단되고 가장 큰 크기에서는 해양포유류 또한 섭식할 것으로 판단된다.

$$
\text { 참고문헌 }
$$

Brodeur RDand Pearcy WG. 1990. Trophic relationships of juvenile salmon off the Oregon and Washingtoncoast. Fish Bull 88, 617-636.

Brodeur RDand Pearcy WG. 1992. Effects of environmental variability on trophic interactions and food web structure in a pelagic upwelling ecosystem. Mar Ecol Prog Ser 84, 101-119.

Bush A. 2003. Diet and diel feeding periodicity of juvenile scalloped hammerhead sharks, Sphyrna lewini, in Kāne'ohe Bay, O'ahu, Hawai'i. Environ Biol Fish 67, $1-11$.

ChibaA. 1998. Ontogeny of Serotonin-Immunoreactive Cells in the Gut Epithelium of the Cloudy Dogfish, Scyliorhinus torazame, with Reference to Coexistence of Serotonin and Neuropeptide Y. Gen Comp Endocrinol 111, 290-298.

Choi Y. 2009. Distribution of the white shark, Carcharodon carcharias and other sharks around the Korean waters. Korean J Ichthyol 21, 44-51.

Compagno LJV. 1984. Sharks of the World. An Annotated and Illustrated Catalogue of Shark Species Known to Date. FAO, Rome.

Fanelli E, Rey J, Torres P and Gil de Sola L. 2009. Feeding habits of blackmouth catshark Galeus melastomus Rafinesque, 1810 and velvet belly lantern shark Etmopterus spinax (Linnaeus, 1758) in the western Mediterranean. J Appl Ichthyol 25 (Suppl. 1), 83-93.

Garman S. 1997. The Plagiostomia-Sharks, Skates, Rays. Benthic Press, Los Angeles, California, U.S.A., 511.

Huh SH, Park JM and Baeck GW. 2006. Feeding habits of Spanich mackerel (Scomberomorus niphonius) in the Southern Sea of Korea. J Korean Fish Soc 39, 35-41.

Jardas I, Šantić M, NerlovićV and Pallaoro A. 2007. Diet composition of blackspotted smooth-hound, Mustelus punctulatus (Rissom, 1826), in the eastern Adriatic Sea. J Appl Ichthyol 23, 279-281.

Kamura S and Hashimoto H. 2004. The food of four species of triakid sharks, Triakis scyllium,
Hemitriakis japanica, Mustelus griseus and Mustelus manazo, in the central Seto Inland Sea, Japan. Fish Sci 70, 1019-1035.

Kim IS, Choi Y, Lee CH, Lee YJ, Kim BJ and Kim JH. 2005. Illustrated Book of Korean Fishes. Kyohak Publ., Seoul, Korea, 615.

KNSO (Korea National Statistical Office). 1990-2009. Fishery Production Survey. Kor Nat'l Stati Office.

Kubodera T, Watanabe H and Ichii T. 2007. Feeding habits of the blue shark, Prionace glauca, and salmon shark, Lamna ditropis, in the transition region of the Western North Pacific. Rev Fish Biol Fish 17, 111-124.

Matallanas J, Carrasson M and Casadevall M. 1993. Observations on the feeding habits of the narrow mouthed cat shark Schroederichthys bivius (Chondrichthyes, Scyliorhinidae) in the Beagle Channel. Cybium 17, 55-61.

McElroy WD, Wetherbee BM, Mostello CS, Lowe CG, Crow GL and Wass RC. 2006. Food habits and ontogenetic changes in the diet of the sandbar shark, Carcharhinus plumbeus, in Hawaii. Environ Biol Fish 76, 81-92

NFRDI (National Fisheries Research \& Development Institute). 2001. Shrimp of the Korean Waters. Nat'l Fish Res Dev Inst 1-188.

Petraitis PS. 1979. Likelihood measure of niche breadth and overlap. Ecol 60, 703-710.

Pinkas L, Oliphant MS and Iverson ILK. 1971. Food habits of albacore, bluefin tuna and bonito in California waters. Fish Bull 152, 1-105.

Preti A, Kohin S, Dewar H and Ramon D. 2008. Feeding habits of the bigeye thresher shark (Alopias superciliosus) sampled from the California-based drift gillnet fishery. Rep CA Coop Ocean Fish Invest 49, 202.

Saidï S, Enajjar S, Bradaï MN and Bouaïn A. 2009. Diet composition of smooth-hound shark, Mustelus mustelus (Linnaeus, 1758), in the Gulf of Gabe's, southern Tunisia. J Appl Ichthyol 25 (Suppl. 1), 113-118.

Sigler MF, Hulber LB, Lunsford CR, Thompson NH, Burek K, Corry-Crowe GO and Hirons AC. Diet of pacific slepper shark, a potential Steller sea lion 
predator, in the north-east Pacific Ocean. J Fish Biol 69, 392-405.

Stehmann MFW. 2002. Proposal of a maturity stages scale for oviparous and viviparous cartilaginous fishes (Pisces, Chondrichthyes). Arch Fish. Mar Res 50, 23-48.

Takeda M. 1982. Keys to Japanese and Foreign Crustaceans. Hokuryukan Press, Tokyo, Japan, 284

Wetherbee BW, Gruber SH and Cortes E. 1990. Diet, feeding habits, digestion and consumption in sharks, with special reference to the lemon shark, Negaprion brevirostris. pp. 29-47. In: Pratt, Jr HL, Gruber SH and Taniuchi $\mathrm{T}$ (ed.) Elasmobranchs as living resources: Advances in the biology, ecology, systematics, and the status of the fishes. NOAA Tech Rep No. NMFS 90 US Dept of Commerce, Seattle, Wash, U.S.A.

Wotton RJ. 1990. Ecology of Teleost Fishes. Champman
Holl, New York, U.S.A., 404.

Yano K. Stevens JD and Compagno LJV. Distribution, reproduction and feeding of the Greenland shark Somniosus (Somniosus) microcephalus, with notes on two other sleeper sharks, Somniosus (Somniosus) pacificus and Somniosus (Somniosus) antarcticus. J Fish Biol 70, 374-390.

Yoon CH. 2002. Fish of Korea with Pictorial Key and Systematic List. Academy Publ Co Seoul, Korea, 747.

Yoon SJ, Kim DH, Kim JW and Baeck GW. 2008. Feeding habits of chub mackerel (Scomber japonicus) in the Southern Sea of Korea. J Korean Fish Soc 41, 26-31.

2010년 3월 15일 접수

2010년 5월 17일 수정

2010년 6월 15일 수리 